LBNL-54862

\title{
Using Energy Information Systems (EIS): A Guidebook for the U.S. Postal Service
}

\author{
Prepared for \\ United States Postal Service \\ Pacific Area \\ Prepared by \\ Dale Foster and Ben Hough \\ Tetra Tech EM Inc. \\ 1230 Columbia Street, Suite 1000 \\ San Diego, CA 92101 \\ and \\ Galen Barbose, William Golove, and Charles Goldman \\ Ernest Orlando Lawrence Berkeley National Laboratory \\ 1 Cyclotron Rd., MS 90R4000 \\ Berkeley, CA 94720-8136
}

October 2004

The work described herein was funded by the Assistant Secretary of Energy Efficiency and Renewable Energy, Federal Energy Management Program, of the U.S. Department of Energy under Contract No. DE-AC03-76SF00098. The authors are solely responsible for any errors or omissions contained in this report. 


\section{Acknowledgements}

The work described herein was funded by the Assistant Secretary of Energy Efficiency and Renewable Energy, Federal Energy Management Program, of the U.S. Department of Energy under Contract No. DE-AC03-76SF00098. The authors are solely responsible for any errors or omissions contained in this report. We would like to thank Ray Levinson, Joe Vanden Berg and John Samuelsen (U.S. Postal Service) and Ab Ream (DOE) for their support on this project. 


\begin{abstract}
The U.S. Postal Service (Postal Service) recently installed Energy Information Systems (EIS) at 30 facilities in California. These systems integrate electric utility meter data acquisition hardware, software, and communication systems to collect, archive, analyze, and display whole-facility energy consumption data. At some point in the future, these systems could also be integrated with sub-meters that measure the electricity consumption of key end-use equipment.

The purpose of this guidebook is to help Postal Service facility managers interpret and act upon energy data available from their EIS, translating the abundance of information these systems provide into knowledge that can be used to reduce energy use and costs. The guidebook first describes basic EIS capabilities and explains the data and reports that Postal Service EIS provide. It outlines a set of strategies for utilizing this information to improve operations and maintenance of building energy use equipment and for facilitating demand response. Finally, the guidebook offers suggestions on creating a routine for tracking and analyzing energy data and integrating this information into regular energy management activities.
\end{abstract}




\section{Contents}

1. Introduction

$\checkmark$ Energy information systems basics

$\checkmark$ EIS at Postal Service facilities in California

$\checkmark$ How to use this guidebook

$\checkmark$ Postal Service EIS assistance

2. Benefits and capabilities of Postal Service EIS

$\checkmark$ Benefits of EIS

$\checkmark$ Capabilities of EIS

3. Getting familiar with facility energy use data

$\checkmark$ Key metrics for facility energy management

$\checkmark$ Load profiles

$\checkmark$ Load duration curves

4. Strategies for using your EIS to improve operations and maintenance

$\checkmark$ Reducing peak demand charges

$\checkmark$ Eliminating inefficient equipment scheduling

$\checkmark$ Improving building energy equipment performance

$\checkmark$ Benchmarking energy use levels

5. Using EIS to facilitate demand response

6. Creating a routine for tracking energy use

$\checkmark$ Weekly reviews

$\checkmark$ Monthly reviews

$\checkmark$ Quarterly reviews

$\checkmark$ Annual reviews

7. Additional information resources 


\section{Introduction}

The U.S. Postal Service (Postal Service) recently installed Energy Information Systems (EIS) at 30 facilities in California. These systems integrate electric utility meter data acquisition hardware, software, and communication systems to collect, archive, analyze, and display building energy use information. In a variety of circumstances, information from EIS can be used to reduce energy costs by 10-15\%. The purpose of this guidebook is to help Postal Service facility managers interpret and act upon the energy data available from the EIS, translating the abundance of information that these systems provide into knowledge that can be directly applied to save energy and reduce energy costs.

This section provides a brief overview of EIS and their basic operation, discusses the EIS currently installed at California Postal Service facilities, identifies the intended audience and uses for this guidebook, and provides sources for additional information for the Postal Service EIS. Sections 2 and 3 describe basic EIS capabilities and explain the information that EIS provide. Section 4 then outlines a set of strategies for utilizing this information to improve the operation and maintenance of building energy systems, and describes the process for implementing these strategies. Section 5 describes the use of EIS for participation in demand response programs. Section 6 offers suggestions on how to create a routine for tracking and analyzing energy data. Additional resources on EIS and other topics discussed in this guidebook are provided in Section 7.

\section{Energy Information System Basics}

EIS are part of a rapidly growing segment of the building energy industry that integrates EIS and advanced metering technology, energy management and control systems, and communications systems, for the purpose of efficiently managing building energy systems.

EIS collect, archive, summarize, and display facility-level (and in some cases, component-level) electricity use data. They allow this data to be accessed by personnel connected to the Internet. Advanced EIS incorporate communications between the utility and customers to facilitate participation in demand response programs. In addition to these single site functions, many systems also provide access to multiple company sites with EIS installed, thus facilitating comparisons between and aggregation of multiple facilities. Systems that perform these functions are often referred to as Enterprise Energy Management systems.

EIS operate in the following manner. Facilities with EIS have interval electric demand meters, which record electricity consumption over 15-minute intervals. In most cases, the meter serves the entire facility and is the same meter used for the utility's billing. However, EIS can also be used in conjunction with sub-meters that measure componentlevel electricity use. The 15-minute energy use data are uploaded through a communications device to an EIS host server, usually the EIS product provider or the electric utility. The host server stores and archives the data off-site. Authorized EIS users are then able to access the database from any computer connected to the Internet. 
The EIS application program installed on the EIS host server provides a user-friendly interface to access the data. The programs are password protected to secure access to the data. The EIS applications have a variety of data visualization, processing, and reporting features. These features allow the user to review and analyze their facility's energy consumption data. The user can also download the data to their computer, where it can be viewed and analyzed with any standard spreadsheet or graphing software.

\section{EIS at Postal Service Facilities in California}

The Postal Service installed EIS at 30 of its largest facilities in California from 2001 through 2003. These systems were installed, in part, as a response to the 2000/2001 California electricity crisis and were funded by the State of California, through the California Energy Commission’s Peak Load Reduction Program.

The UtilityVision ${ }^{\circledR}$ system (UtilityVision) was installed at 24 Postal Service facilities in regions of California outside of the San Diego Gas \& Electric (SDG\&E) service territory. UtilityVision is installed in Processing and Distribution Centers (P\&DC), Bulk Mail Centers (BMC), and Air Mail Centers (AMC) - all large facilities with loads in excess of 500 kilowatts (kW), and several with loads over two megawatts (MW). This system was originally developed and installed by CMS Energy -Viron Energy System to support energy savings performance contracting. CMS Energy -Viron Energy System has subsequently become part of Chevron Energy Solutions, a wholly owned subsidiary of ChevronTexaco Corporation.

The KWickview Online Energy Monitor system (KWickview) was installed at six Postal Service facilities in the SDG\&E service territory. These six facilities include two P\&DCs, each with loads greater than $500 \mathrm{~kW}$, and four smaller mail facilities, with loads of 50 to $100 \mathrm{~kW}$. This system was developed by ABB Inc. (originally called Online Energy Monitor). SDG\&E has obtained rights to the system and calls it KWickview.

\section{How to Use this Guidebook}

This guidebook is intended for Postal Service personnel working in energy management at the facilities with access to the installed EIS programs. Its intent is to de-mystify the process of using EIS data for energy management. By using examples with actual EIS data from Postal Service facilities, the guidebook illustrates how this information can be processed and viewed to yield knowledge about energy use that can ultimately result in cost and energy savings.

This guidebook assumes the reader has a working knowledge of the operation of the EIS at their facility. It is designed to augment the EIS product supplier's user manual and training materials. It does not cover the fundamental commands to log on, set up parameters, and navigate the EIS programs. Please refer to those documents for assistance if you are new to using the EIS programs. 


\section{Postal Service EIS Assistance}

For assistance in accessing your EIS account, contact the following:

\section{UtilityVision}

Website: http://www.utilityvision.com/logon.asp

Chevron Energy Solutions Company, a Division of Chevron U.S.A. Inc.

12980 Foster Drive, Suite 400

Overland Park, Kansas 66213-2649

Phone: 913-563-3500

Email: uvsales@chevrontexaco.com

KWickview Online Energy Monitor

Website: www.kwickview.sdge.com

San Diego Gas \& Electric Company

Demand Response Programs

Phone: 1-866-377-4735

Email: kwickview@sempreautilities

Section 7 contains additional technical information resources about EIS and related topics. 


\section{Benefits and Capabilities of the Postal Service EIS}

This section provides an overview of the benefits and capabilities of the Postal Service EIS.

\section{Benefits of EIS}

EIS assist energy managers and other decision makers in managing facility energy use and costs. In particular, EIS can be used to:
A. Monitor energy use to reduce peak demand charges
B. Identify instances of inefficient equipment scheduling
C. Facilitate peak shaving measures
D. Better understand historical energy usage patterns and costs
E. Identify maintenance problems with energy end-use equipment
F. Evaluate the impact of energy efficiency and load management projects
G. Automatically respond to utility demand response program curtailment events
H. Verify performance in utility demand response programs
I. Verify utility bills
J. Compare the cost of alternative electric rates

\section{Capabilities of EIS}

The EIS installed at Postal Service facilities in California have the capability to measure and track a facility's energy use, provide an archive of the data, process the data for a variety of reports, aggregate and compare data with other facilities with the same EIS, and provide near real time energy data.

Most EIS programs have the capability to deliver the following types of reports:

- Summary statistics - Energy use and maximum demand levels for any user-specified time period.

- Load Profiles - Time series graphs of electricity demand. Load profiles for different time periods or facilities can be superimposed for comparison. KWickview can also display average weekday and weekend profiles. Load profile data is also available in tabular form, showing the average demand for each 15-minute interval during a day.

- Load duration curves - A frequency distribution curve showing the demand level as a percent of time.

The EIS at Postal Service facilities also have special capabilities intended to facilitate demand response.

- Notification systems to alert managers that energy demand is nearing the current billing peak or other utility events, via pager, phone, or email. 
- Historical curtailment reports, which provide a record of scheduled and actual load curtailments.

- Load control functions that can be used to automatically reduce air conditioning and lighting demand to pre-specified levels, in response to utility demand response program events. 


\section{Getting Familiar with Facility Energy Use Data}

The first step in using EIS data for energy management is to become familiar with the energy consumption patterns at your facility. This section defines basic metrics for understanding facility energy use and explains how these metrics can be used to become better acquainted with facility energy use. It also describes two common formats for viewing time-series energy data: load profiles and load duration curves. Each of these techniques for viewing energy data has distinct advantages and applications.

\section{Key metrics for facility energy management}

A metric refers to a measure used for comparison and evaluation. The metrics most useful for facility energy management are related to two basic quantities: electrical energy consumption and demand. Electrical energy consumption refers to the amount of electricity used over a period of time and is typically measured in units of kilowatt-hours (kWh). Demand, also referred to as power or load, represents the rate at which electricity is being used at a particular moment in time. It is typically measured in units of kilowatts $(\mathrm{kW})$ or megawatts (MW). When measured with a standard utility interval meter, the demand is generally given in terms of a 15-minute average.

The EIS installed at Postal Service facilities provide facility managers with data that can be used to generate various metrics for understanding and evaluating the energy consumption at their facility. Some of these metrics are provided directly by the EIS software interface. Others can be calculated manually by the EIS user, by first downloading energy consumption data through the EIS interface and then performing simple calculations with standard desktop spreadsheet software.

Listed below are a number of key metrics, along with a brief explanation of how these metrics can be used by facility managers to become better acquainted with patterns of energy use.

- Daily energy use ( $k W h / d a y)$. Facility managers can determine the total energy use on any day, either by generating EIS reports or by importing 15-minute interval data into a spreadsheet and summing the interval data for the day.

o By regularly monitoring daily energy use, facility managers can quickly detect O\&M problems associated with unusual levels of energy use.

o If a specific condition were known to exist on a particular day (for example, an exceptional quantity of mail processed or extreme weather), a facility manager could easily determine the electricity use on that day, and by comparing to other days, assess the extent to which energy use was affected.

o Facility managers may find it useful to calculate basic descriptive statistics for the daily energy use, such as the maximum, minimum, average, and standard deviation. These statistics can be easily calculated with standard spreadsheet software and can help facility managers gain a better understanding of the overall variation in energy use at their facility. 
o Facility managers can also calculate the average daily energy use over a class of day types (e.g., all Mondays, all weekdays or weekend days, all holidays, etc.). This requires importing interval data into a spreadsheet and sorting it according to the relevant day type.

o Facility managers can create a chart that compares the energy use of each day to the corresponding average or maximum daily temperature in their area.

- Monthly or seasonal energy use ( $\mathrm{kWh} / \mathrm{month})$. Facility managers can generate EIS reports that show the electricity consumption over any monthly or seasonal period.

o Facility managers can use this metric to compare electricity consumption for different months/seasons of the year to see how monthly/seasonal factors affect electricity consumption.

o They can also compare usage in the same month or season of different years, to see if changes in energy use are concentrated in particular periods.

- Annual energy use $(\mathrm{kWh} / \mathrm{yr})$. Facility managers can generate EIS reports that show the annual electricity consumption at their facility.

o This metric can provide a useful measure of energy use at a particular facility, independent of seasonal cycles in weather or mail processing activity.

- Maximum demand $(\mathrm{kW})$. By reviewing load profiles and/or EIS reports, facility managers can determine the maximum demand within any time span (e.g., a particular day, week, month, or year). By importing interval data into a spreadsheet and sorting by time of day, they can also determine the maximum demand during their utility's on-peak time-of-use period. Facility managers can use data on maximum demand for the same purposes as described above, for daily, monthly, and annual energy use.

- Load factor. This metric refers to the ratio of the total energy use in some period to the product of the maximum demand and the number of hours in the period (see equation below).

$$
\text { Load Factor }=\frac{\text { Energy Use }}{\text { Maximum Demand } \times \text { Number of Hours }}
$$

The load factor, which can take on any value between zero and one, is a way of describing the pattern of energy use at a facility - in particular, whether the demand is "flat" or "peaky." A facility with electricity demand that is relatively constant will tend to have a load factor close to one; whereas a facility with demand that is much higher at some times than at others will have a load factor closer to zero.

- Baseload $(\mathrm{kW})$. This metric refers to the minimum demand level occurring at a facility over a specified time period. A facility's baseload is comprised primarily of equipment that runs continuously and/or during unoccupied hours. As a result, changes in a facility's baseload can have substantial effects on its total energy consumption. 
- Energy intensity ( $\mathrm{kWh} / \mathrm{yr} / \mathrm{sq}$. ft.). This metric normalizes the annual energy use at a facility to its floor area. It is most relevant for facilities where lighting and airconditioning represent the majority of the electricity use, since these end-uses typically scale with the size of the facility's floor area. This particular metric can be useful for comparisons of energy use between facilities, particularly when they are in similar weather zones (and therefore have similar cooling loads).

\section{Load Profiles}

A load profile is a chart that displays electricity demand over time, typically for a 24-hour period. They can be used to understand the regular diurnal pattern of energy use at a facility, as well as to detect changes in energy use and demand due to weather, equipment modifications, operational changes, or other factors. They are also essential tools for investigating demand spikes, allowing the facility manager to determine the time of day that the demand spike occurred and deduce its cause.

The Postal Service's EIS programs allow flexibility in selecting the range of data that can be included in the load profiles and the manner in which it is displayed. The following are a few of the many ways that data can be organized by the EIS to generate load profiles:

- Any specific day’s load profile

- Average load profile over a time period for all days in the period, for weekdays, or for weekend days

- Load profile for the day with the maximum demand

- Normalized for facility square footage, hours of operation, or units of production

- Any of the above load profiles can be displayed either for a single facility, for multiple facilities superimposed on a single graph, or for multiple facilities aggregated into a single load profile

In addition, facility managers can download the interval meter data through the EIS interface. Using standard desktop spreadsheet and graphing software, they can construct various average load profiles (e.g., the average load profile for all Mondays in summer months) and plot any combination of load profiles on the same chart. 
Average of All Selected Accounts

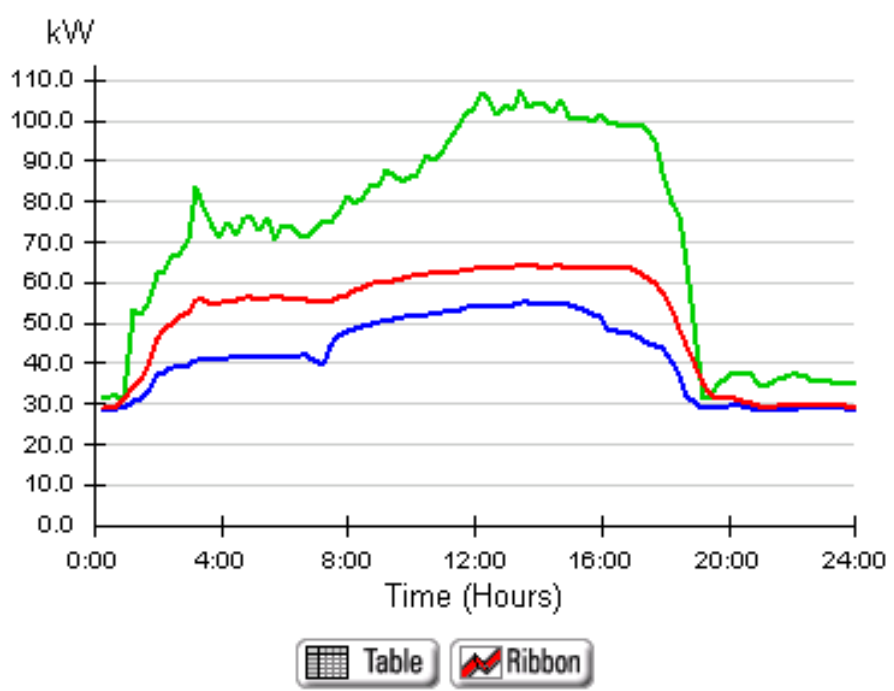

\section{Redraw}

\section{Select Account}

Average of All Selections

Normalize:

None

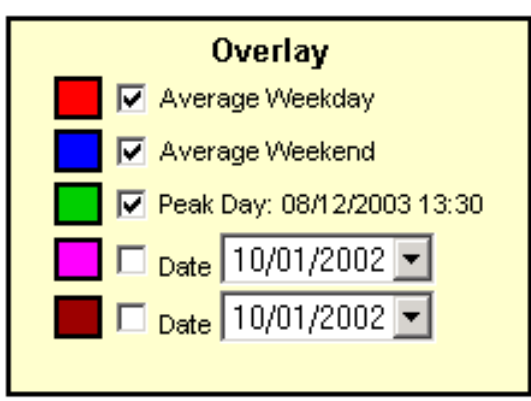

Figure 1. Annual load profile for a Postal Service facility

Figure 1 shows three load profiles for a small Postal Service facility. The lowest line in the graph is the weekend day's diurnal energy use pattern averaged over a one-year period. The middle line is the average weekday load profile during the one-year period. The energy use on the weekdays and weekends follow the same pattern, with lower energy use during the hours of operation (roughly 2:00 am to 7:00 pm). The baseline energy use is the same, about $30 \mathrm{~kW}$, on the weekdays and the weekend. Baseline usage shows how thoroughly a facility is shut down during non-work hours. Facilities with continuous operation would be expected to have high baseline energy use levels.

The top line in Figure 1 is the daily load profile on the day when the maximum demand level occurred. In this example, the peak demand occurred in the afternoon on August $12^{\text {th }}$, probably on a day with high outdoor temperatures requiring high levels of cooling in the facility. However, energy use was also relatively high during early morning hours, indicating that the additional demand may have been associated with non-cooling loads as well. Note this line is much more irregular because it is only one-day's data; whereas the other lines are the averages of a total of 365 days data.

Facility managers are encouraged to examine the load profiles for their facility for different days during the year in order to understand how their facility's energy consumption is affected by seasonal and weekly mail processing cycles and by changes in weather patterns. The more that they review their facility's load profile, the better they will be able to detect abnormal energy consumption patterns and avoid unnecessary energy costs. 


\section{Load Duration Curves}

Load duration curves are another useful tool for understanding facility energy use patterns and to identify energy cost savings opportunities. Similar to a load profile, a load duration curve is developed from 15-minute interval meter data and can span any time period the user selects (e.g., a day, week, month, or year). However, whereas load profiles display facility load data chronologically, load duration curves display load data ordered from the highest value to the lowest value. The X-axis of a load duration curve shows the number of hours or the percent of time that demand is greater than or equal to the value shown on the Y-axis. Load duration curves are particularly useful for assessing the potential for reducing a facility's peak demand. They can often reveal that a reduction in demand during only a small number of hours can dramatically reduce peak demand, thereby generating savings on billing demand charges and facilitating participation in demand response programs.

Load duration curve for 05/01/2003 - 04/30/2004

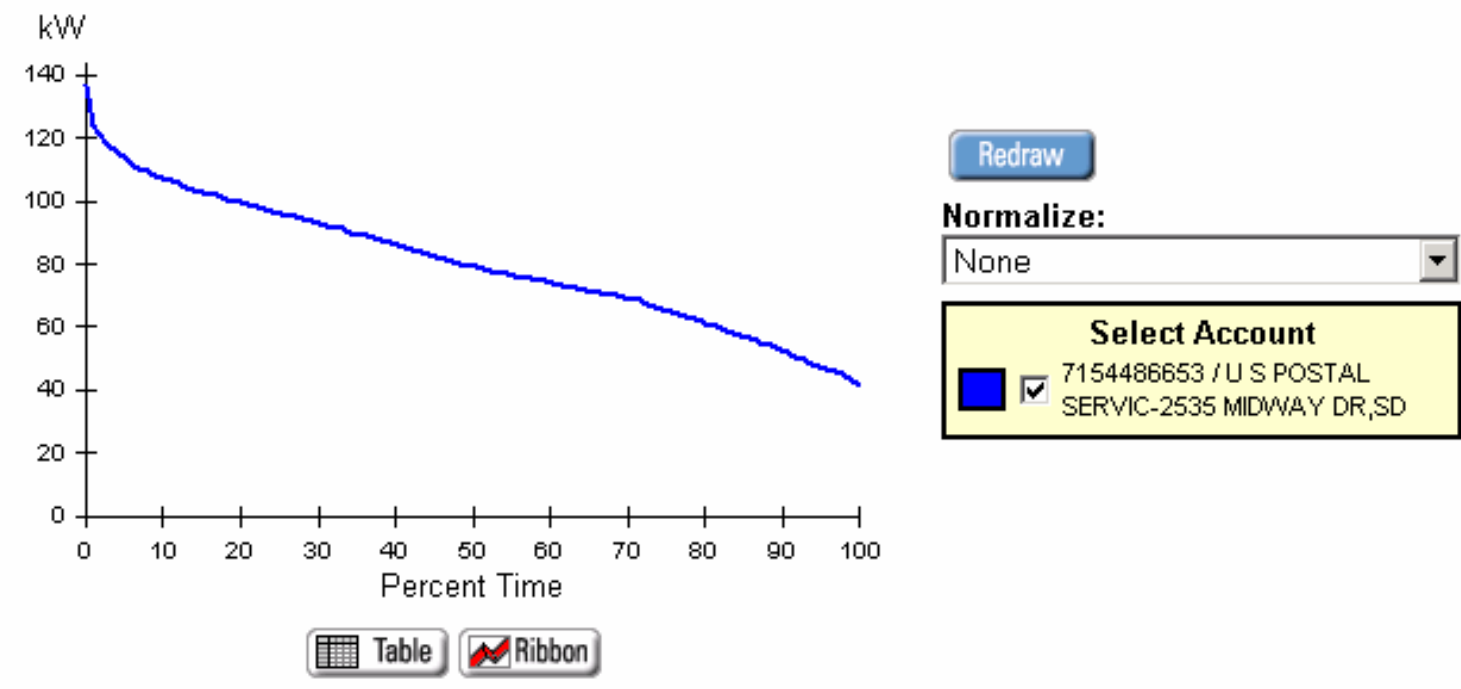

Figure 2. Load duration curve for a Postal Service facility

Figure 2 shows a load duration curve for a small Postal Service facility, covering the period from 5/1/2003 to 4/30/2004. From this load duration curve we can observe that the base load never is less than about $40 \mathrm{~kW}$ and the peak demand is about $135 \mathrm{~kW}$. However, the facility's peak demand is above $120 \mathrm{~kW}$ for only $2-3 \%$ of the time throughout the year. The small percent of time that the demand level is near its maximum indicates a potential opportunity for reducing peak demand charges. 


\section{Strategies for Using Your EIS to Improve Operations and Maintenance}

This section describes strategies that will help Postal Service personnel use the information available from the EIS to better manage energy use at their facility. Key EIS reports are highlighted, including guidance on what to look for in these reports, to direct you towards energy and cost saving opportunities and improved operations and maintenance of your facilities' energy systems. Identifying potential opportunities using the EIS programs is just the beginning. To be successful, potential opportunities gleaned from the EIS programs will need to be investigated, validated, and implemented within the facility.

The following strategies for using your EIS are discussed in this section:

1. Reducing peak demand charges

2. Eliminating inefficient equipment scheduling

3. Improving building energy equipment performance

4. Benchmarking energy use levels 


\section{Reducing peak demand charges}

As with all large facilities, Postal Service facilities incur electric utility demand charges based on the highest, 15-minute average power demand each month. For many utility rates, the largest demand charge is based on the highest demand that occurs during the utility's on-peak time-of-use (TOU) period (see Table 1 for the on-peak TOU period of each of California's major electric utilities). Depending on the particular tariff on which they are served, demand charges can account for $20-30 \%$ of a Postal Service facility's electric bill. However, EIS data can be a valuable tool for reducing a facility's peak demand and the associated billing demand charges. Reductions in peak demand also help to maintain the reliability of the electric grid during periods when demand for electricity in the region is high, and put downward pressure on electricity prices.

Table 1. California electric utilities' on-peak TOU periods.

\begin{tabular}{|ccll|}
\hline Utility & $\begin{array}{c}\text { Rate } \\
\text { Schedule }\end{array}$ & \multicolumn{1}{c|}{ Summer Season } & \multicolumn{1}{c|}{ Winter Season } \\
\hline PG\&E & A-10 & Summer On-Peak, May 1 - Oct 31 & $\begin{array}{l}\text { Winter On-Peak, Nov 1 - Apr 30 } \\
\text { No on-peak in winter }\end{array}$ \\
& E-19 & 12:00 noon - 6:00 pm weekdays & \\
\hline SDG\&E & AYTOU & Summer On-Peak, May 1 - Sep 30 & Winter On-Peak, Oct 1 - Apr 30 \\
& ALTOU & 11:00 am - 6:00 pm weekdays. & 5:00 pm - 8:00 pm weekdays \\
& & & \\
\hline SCE & TOU-8 & Summer On-Peak, Jun - Sep. & Winter On-Peak, Oct - May \\
& & 12:00 pm - 6:00 pm weekdays & No on-peak in winter \\
& & & Low Peak Season, Nov 1 - May 31 \\
LADWP & A-3 & High Peak Season, Jun 1 - Oct 31 & 10:00 am - 12:59 pm weekdays \\
& & 1:00 - 4:59 pm weekday & 5:00 pm - 7:59 pm weekdays \\
& & & Winter Season, Oct 1 - May 31 \\
& & & No super peak in winter \\
\hline SMUD & GS-TOU & Summer Season, Jun 1 - Sep 30 & \\
& & Super Peak 2:00 - 8:00 pm weekdays & \\
\hline
\end{tabular}

\section{Benefits of reducing peak demand}

Reducing peak demand:

- Reduces electric utility demand charges

- Enhances the reliability of the grid

- Dampens spot-market price volatility

- Reduces the number of new power plants that must be constructed to meet growing peak demand in the region 


\section{Approach}

An energy manager can reduce peak demand through the following activities:

1. Use a demand alarm to provide notification when demand at the facility reaches a pre-specified threshold, at which point manual actions can be undertaken.

2. Review historical peak demand data and related metrics to establish benchmarks and develop an understanding of the factors that affect peak demand at your facility.

3. Analyze load duration curves for individual months to determine the peak demand reduction potential, as indicated by the "peakiness" of the load duration curve.

4. Analyze load profiles on the days with the highest demand each month to identify the timing of peak demand and to look for demand spikes and other unusual patterns in energy usage.

5. Identify equipment that can temporarily be curtailed or shifted to other periods when demand at the facility is high.

6. Identify opportunities to permanently reduce demand during on-peak periods, either by making energy efficiency improvements or by engaging in conservation efforts.

7. Use automated load controls to curtail or reduce the operation of non-essential equipment when demand at the facility reaches a pre-specified threshold.

\section{Discussion}

There are several general ways to reduce peak demand and the associated demand charges at a facility. One is to identify and eliminate demand spikes. These are very short-term increases in demand associated with relatively infrequent events, such as motor start-ups. A second is to shift certain processes and activities, on either a permanent or an occasional basis, from on-peak to off-peak periods. This type of strategy can be employed when certain loads cannot be eliminated, but they can be scheduled in a flexible manner. A third way to reduce peak demand is to curtail or reduce the operation of non-essential equipment during periods when demand at the facility is particularly high - for example, by turning off unused lighting and raising thermostat set-points. Finally, peak demand can be reduced by engaging in energy efficiency and conservation efforts targeted at equipment that operates during the utility's on-peak period - for example, by installing high efficiency lighting, motors, and HVAC equipment.

All of these techniques for reducing peak demand can be facilitated by information available through the EIS. First, EIS data can be used to assess the potential for peak demand reductions. Second, by establishing and tracking benchmarks and reviewing load profiles, facility managers can better understand trends in peak demand at their facility. Finally, EIS can also be used to trigger demand alarms and/or automatically curtail certain equipment when the facility's demand reaches a pre-specified threshold.

As an example of how EIS can be used to assess peak demand reduction potential, consider the load duration curve for a P\&DC shown in Figure 5. This is a fairly typical 
curve for these types of facility. What can be seen on the left side of the curve is the short duration of the highest demand levels over the course of the month selected (September 2003). Note that, by clicking on the "Table" button, this data can also be viewed in tabular form, which allows a more precise review of the numbers (see Figure 6). The load duration curve indicates that the peak demand for this facility was 2,496 $\mathrm{kW}$ during the month of September. The summary statistics table shows that this peak occurred at 7:30 pm on September 5.

This load duration curve data indicates that for one percent of the time in this month (about 7 hours) the demand was above 2,323 kW. Thus the difference between peak demand and 1 percent demand $(2,496-2,323=) 173 \mathrm{~kW}$ occurred during just 7 hours in the month and determined the peak demand charges on the facility electric bill for the month. At a demand charge of \$10/kW-month, this amounts to \$1,730 in charges that could have been avoided with demand reductions of at most $173 \mathrm{~kW}$ during those critical seven hours. If a demand reduction of similar magnitude were achieved in every month, this would translate to savings of more than $\mathbf{\$ 2 0 , 0 0 0}$ over the course of a year! A similar set of calculations shows that just $2 \%$ of the hours during the month account for the highest $240 \mathrm{~kW}$ of peak demand. If demand were reduced during these hours, billing demand charges could be reduced by approximately $\mathbf{\$ 2 , 4 0 0}$ in the month or $\mathbf{\$ 2 8 , 8 0 0}$ over the year. This example illustrates how reviewing load duration curves for individual months can allow facility managers to easily identify the magnitude of effort needed to reduce demand charges for their facility.

Load duration curve for 09/01/2003 - 09/30/2003

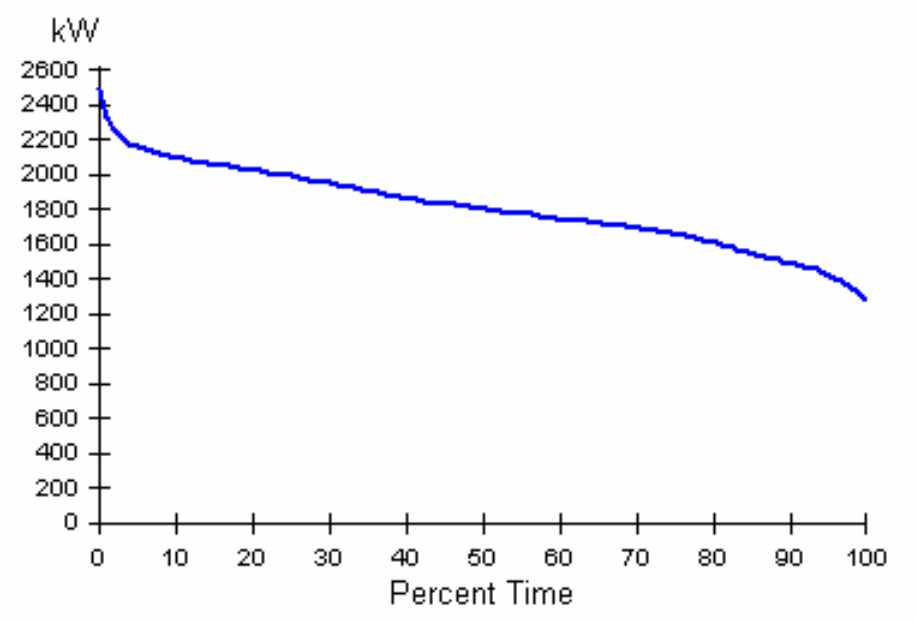

\section{Redraw}

Normalize:

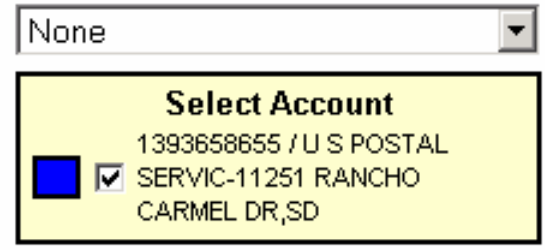

吿 Table 1 Ribbon

Figure 5. Monthly load duration curve 


\section{Continue}

Load duration curve for 09/01/2003 - 09/30/2003

\begin{tabular}{|r|r|r|}
\hline Percent Time & 1393658655 / U S POSTAL SERVIC-11251 RANCHO CARMEL DR,SD \\
\hline Peak & 2,496 \\
\hline $1 \%$ & 2,323 \\
\hline $2 \%$ & 2,256 \\
\hline $3 \%$ & 2,218 \\
\hline $4 \%$ & 2,179 \\
\hline $5 \%$ & 2,160 \\
\hline $6 \%$ & 2,150 \\
\hline $7 \%$ & 2,131 \\
\hline $8 \%$ & 2,122 \\
\hline $9 \%$ & 2,102 \\
\hline $10 \%$ & 2,093 \\
\hline $11 \%$ & 2,083 \\
\hline $12 \%$ & 2,074 \\
\hline $13 \%$ & 2,064 \\
\hline $14 \%$ & 2,064 \\
\hline $15 \%$ & 2,054 \\
\hline $16 \%$ & 2,054 \\
\hline $17 \%$ & 2,045 \\
\hline $18 \%$ & 2,035 \\
\hline & \\
\hline
\end{tabular}

Figure 6. Monthly load duration curve in table form

Profile for Selected Accounts for the Month of September

\section{Redraw}

Normalize:

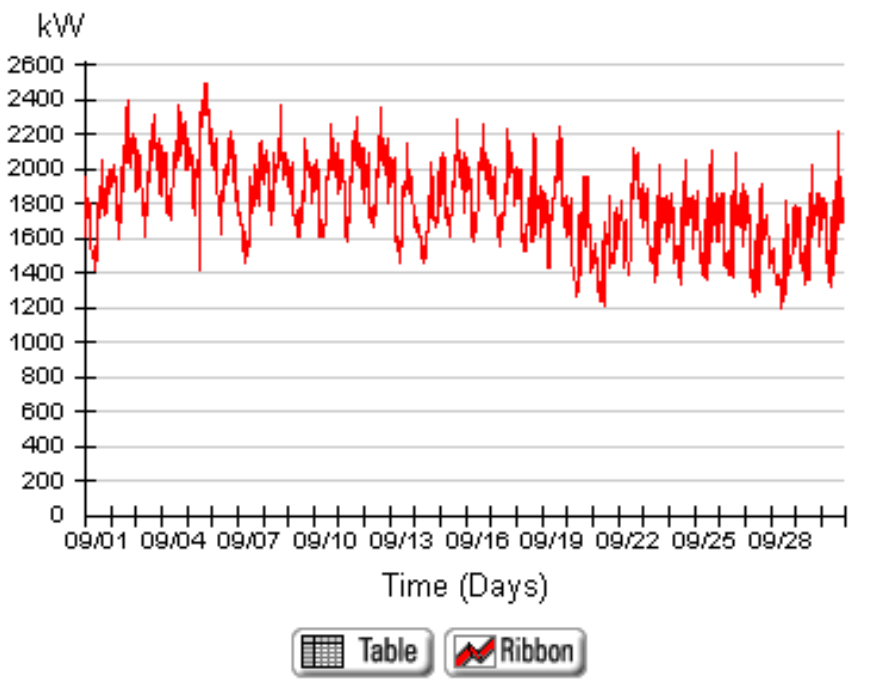

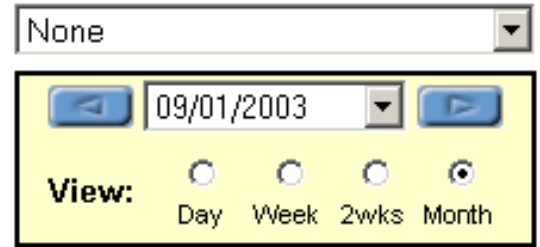

Overlay Accounts

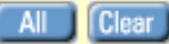

1393658655 U S POSTAL

$\checkmark$ SERVIC-11251 RANCHO CARMEL DR,SD ( $\mathrm{KW}$ )

Figure 7. Monthly load profile 
Load profiles are another key tool for energy managers to reduce peak demand. As an example, consider the one-month load profile for a P\&DC, shown in Figure 7 . The profile shows the daily and weekly cycles in electricity demand at the facility, as well as the overall decreasing trend over the course of the month.

Load profiles can be used by energy managers to identify unusual patterns in electricity usage, such as demand spikes, which may be caused by an equipment problem or an energy wasting action or process in the facility. Such occurrences should be viewed as opportunities to save energy and improve equipment operation. As an example, observe in Figure 7 the large fluctuation during one day early in the month. To investigate the profile in more detail, we have selected a one-week time period within this month, shown in Figure 8. We see that the anomaly occurs on September $5^{\text {th }}$. By using the pull down menu to select "09/05/2003, clicking the "Day" view, then clicking on the "redraw" button, the daily load profile shown in Figure 9 is displayed. We can now see the details of the high fluctuation in demand that was noted on the monthly profile. We see that at about 1:00 pm there was a sudden reduction of $600 \mathrm{~kW}$ (from $2150 \mathrm{~kW}$ to $1500 \mathrm{~kW}$ ). We might speculate that this was caused by some energy-intensive process equipment going off-line. The load remained low until about 3:00 pm when the load increased dramatically by $1000 \mathrm{~kW}$, and remained near this level for the remainder of the day.

Profile for Selected Accounts on 09/01/2003

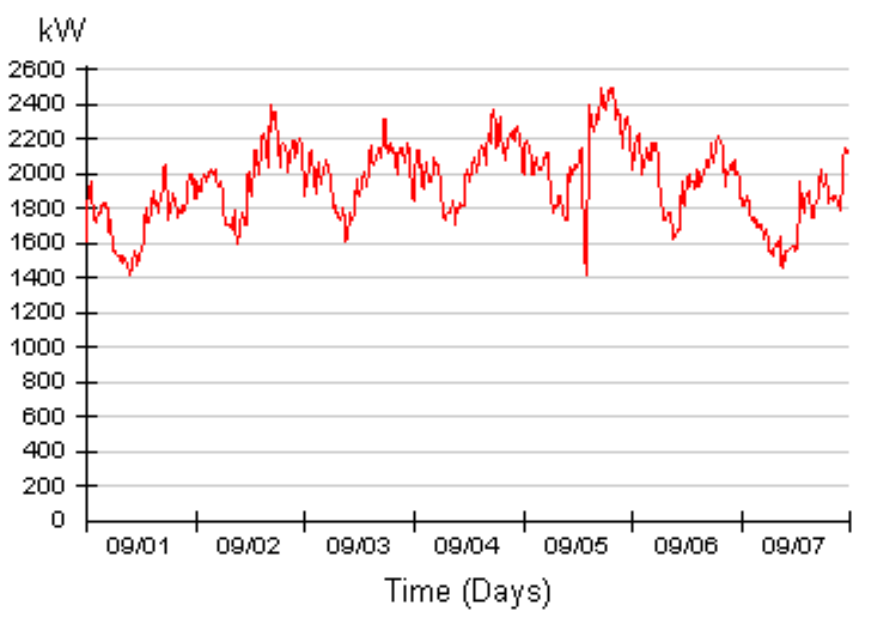

Redraw

Normalize:

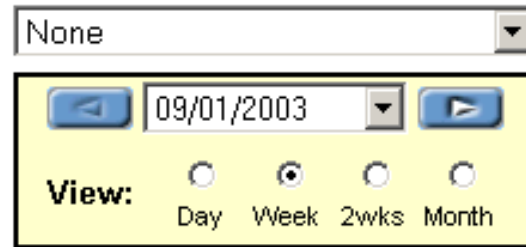

Overlay Accounts

All Clear

1393658655 U S POSTAL SERVIC-11251 RANCHO CARMEL DR,SD (KM)

Figure 8. Weekly load profile 
Profile for Selected Accounts on Friday, 09/05/2003

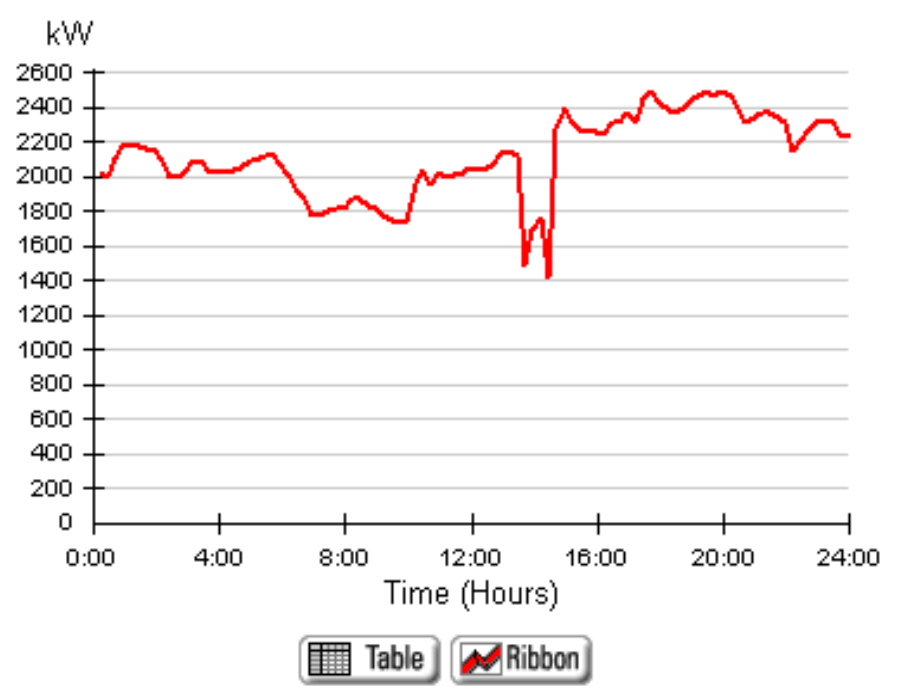

\section{Redraw}

Normalize:

None

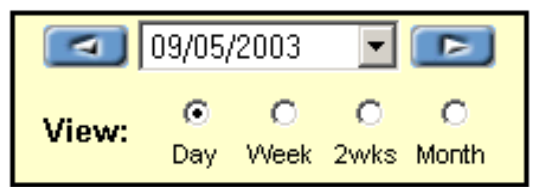

Overlay Accounts

All Clear

1393658655 U S POSTAL

V SERVIC-11251 RANCHO

CARMEL DR,SD (KM)

\section{Figure 9. Daily load profile}

- Perhaps related to this load reduction, the facility's peak demand for the month $(2500 \mathrm{~kW})$ occurred a short time later that day. The peak demand on this day was about $100 \mathrm{~kW}$ higher than on any other day in this month. If this single day's 100 $\mathrm{kW}$ additional demand could have been prevented, at a billing demand rate of $\$ 10 / \mathrm{kW}, \$ 1,000$ would have been saved from the monthly electric bill. Using the facility's EIS to identify this type of opportunity can rapidly add up to substantial energy cost savings.

The Postal Service EIS also have several other capabilities that can be used to reduce peak demand and billing demand charges. The EIS can be configured to send alarm notifications to key personnel as peak demand thresholds are approached, at which time facility personnel can then manually reduce loads. The UtilityVision program also has the capabilities to automatically curtail pre-configured lighting and HVAC compressors by up to $50 \%$ during the highest demand time periods. Both of these EIS functions (demand alarms and load control) can be particularly useful for facilitating participation in utility demand response programs.

UtilityVision User Tip: "User Alarms" is an option within your EIS so that you can be alerted when critical demand thresholds are being approached. This can allow you time to reduce curtailable loads. These reductions can be implemented with manual shut down's of load or with pre-determined automated load shedding systems. Identify in advance what loads can be reduced when needed. 


\section{Eliminating inefficient equipment scheduling}

The EIS programs can be used to identify and eliminate inefficient equipment scheduling that can be wasting energy and costing money. Examples include process equipment left on when not in use for extended periods, air compressors that are run continuously even though there are extended periods when they are not needed, loading dock or exterior lights left on throughout the day, and HVAC equipment that runs continuously throughout unoccupied hours. Another common example of inefficient scheduling would be turning on many pieces of equipment at the same time.

\section{Benefits of eliminating inefficient equipment scheduling}

Eliminating inefficient equipment scheduling:

- Saves energy and save money

- Allows for possible early identification of equipment problems

- Improves equipment reliability.

\section{Approach}

An energy manager can implement the following approach using EIS to eliminate inefficient equipment scheduling:

1. Regularly review load profiles for your facility to identify unusual patterns of electricity use that may be associated with unnecessary equipment use - for example, equipment cycling during non-operating hours.

2. Compare daily load profiles with historical load profiles to identify changes that may be indicative of inefficient equipment scheduling - for example, by comparing the facility baseload and the timing of shut-down and start-up activities.

3. Compare your facility's load profile and energy use metrics with similar Postal Service facilities to identify differences associated with alternative energy management practices.

\section{Discussion}

The following example illustrates how the load profiles of two Postal Service facilities can be compared to identify differences potentially associated with alternative energy management practices. Figure 10 shows the average weekday load profile for the two Postal Service facilities over calendar year 2003. Figure 11 shows the same facilities' average weekend day load profile over the same time period. 


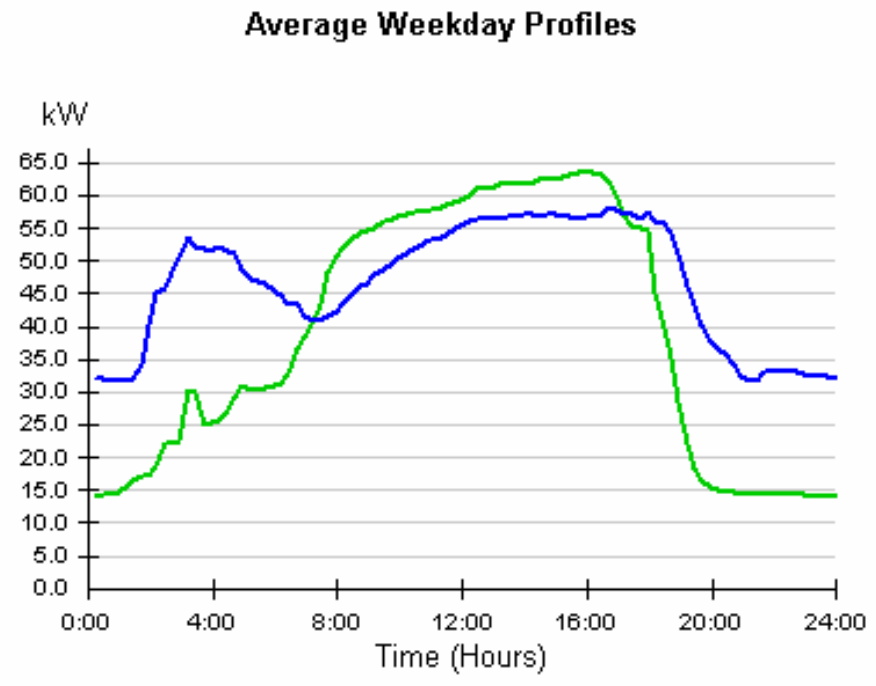

\section{Redraw}

Profile Type:

Average Weekday

Normalize:

None

\begin{tabular}{|c|c|}
\hline Select Account \\
$\square \sqsubset$ Average of All Selections \\
6765803956 / U S POSTAL \\
$\square$ SERVIC-1157 W MISSION \\
AVE,ES \\
$\square$ 0423627034 i U S POSTAL \\
SERVIC-5045 SHOREHAM PL,SD
\end{tabular}

䍹 Table Ribbon

Figure 10. Comparison of two facilities' average weekday load profile

Average Weekend Profiles

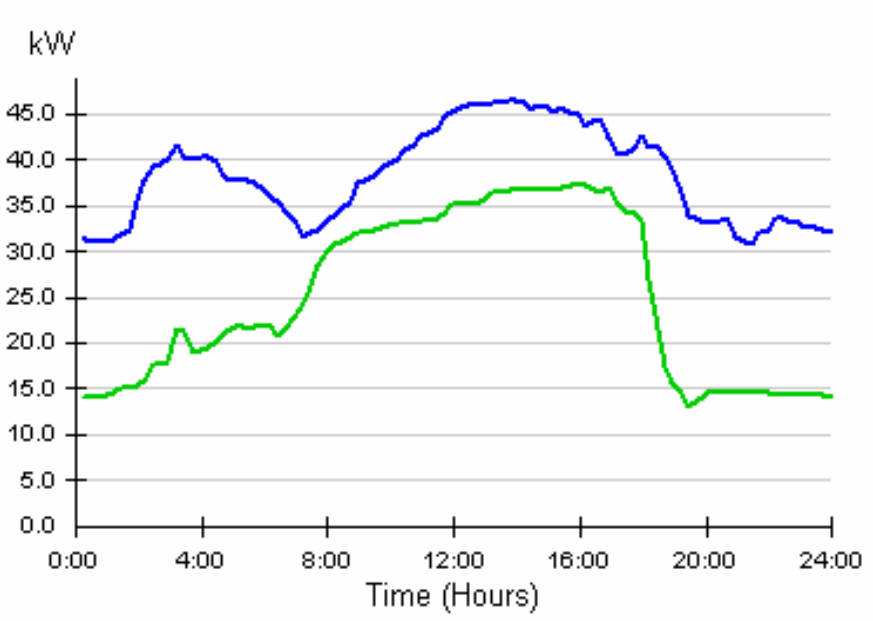

彗 Table Ribbon

\section{Redraw}

Profile Type:

Average Weekend

Normalize:

None

\section{Select Account}

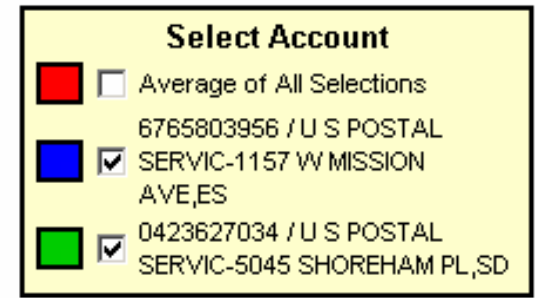

Figure 11. Comparison of two facilities' average weekend day load profile

Note the differences between the load profiles of these two facilities. One facility reduces demand quite dramatically in the evening hours and then ramps demand back up as the early morning work increases. At the other facility, demand drops much less dramatically during evening hours, and second peak load occurs at about 4:00 am. The differences in the load profiles between these facilities may, in part, be explained by 
differences in their mail processing operations. However, they may also indicate that one facility may be able to shut down additional equipment and reduce energy use during evening hours.

In large facilities, where the majority of the EIS programs are installed, postal employees occupy the facilities continually and the loads are larger. Figure 12 shows one day's load profile for a P\&DC facility. This is typical of a daily load profile in a larger facility. The average demand at this facility ranges from about $900 \mathrm{~kW}$ in mid-day to $1,300 \mathrm{~kW}$ in the early morning hours. There probably are several energy saving opportunities in this large facility, however, it will take further investigation within the facility to identify and assess them. Facilities have their own "signature" load profile. Routinely viewing load profiles allows you to quickly recognize irregularities that should be investigated.

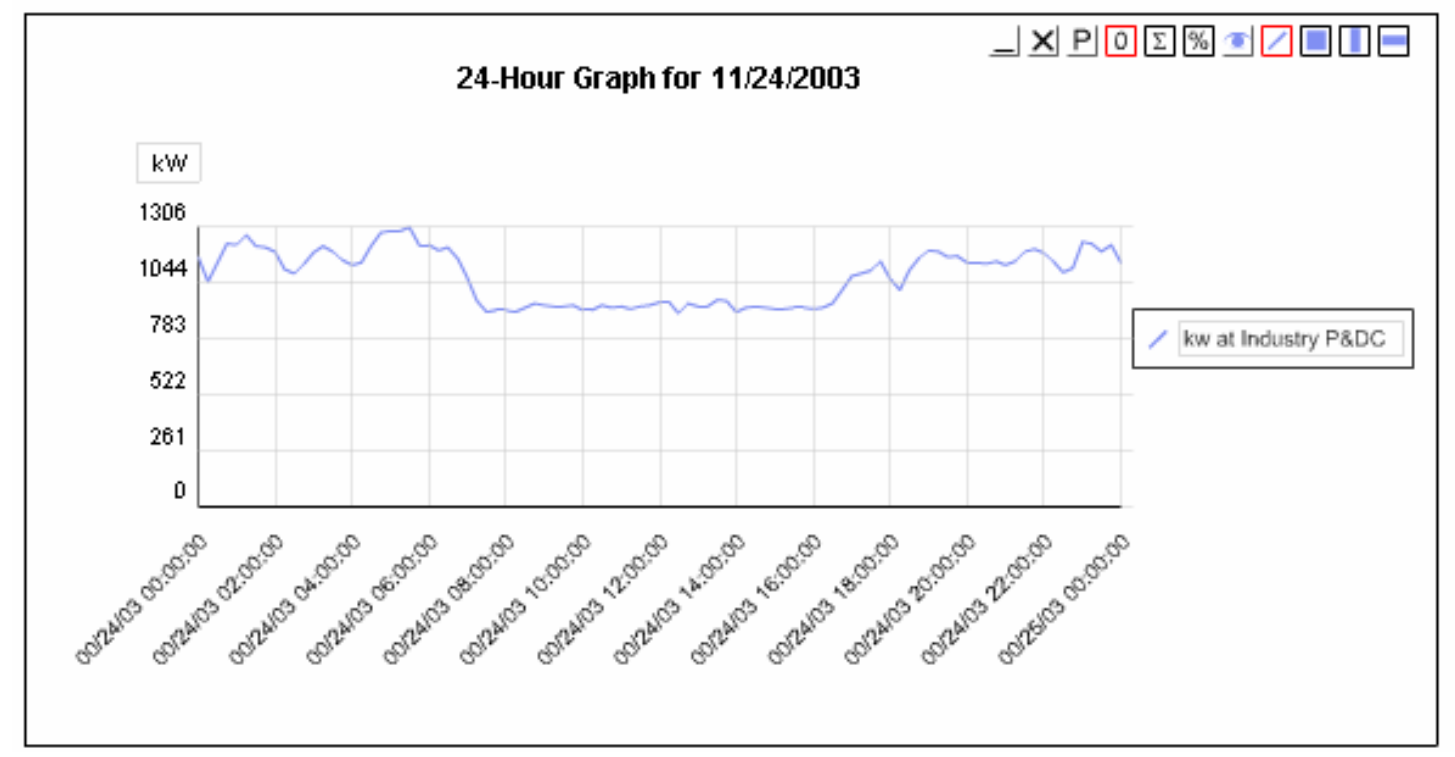

Figure 12. Daily load profile from a P\&DC 


\section{Improving building energy equipment performance}

EIS systems can help identify building energy equipment that is not performing properly and exhibiting poor or unusual energy utilization. Typically, this would be associated with heating, ventilating, and air conditioning (HVAC) and compressed air systems. Once the equipment in need of attention is identified, proactive maintenance can be performed to improve and optimize building energy systems’ performance. It is much more cost effective to maintain equipment in proper working condition than to repair it after it has failed.

\section{Benefits}

Using EIS to improve building energy equipment performance:

- Saves energy and reduces utility costs.

- Provides early identification of potential equipment problem.

- Improves equipment reliability.

\section{Approach}

An energy manager can use EIS and the following approach to optimize equipment performance:

1. Review daily load profiles and energy metrics to compare with expected energy use patterns. Include review of profiles when facility workloads are at their minimum.

2. Look for patterns and unusual anomalies in the load profiles, as well as long-term trends that might indicate equipment degradation.

3. Compare with other daily load profiles at your facility or with other similar Postal Service facilities.

4. Investigate unusual loads for causes by malfunctioning or inefficient equipment.

\section{Discussion}

A good approach for reviewing load profiles is to select days when the plant operations are expected to be at reduced levels. This helps to remove process equipment loads from the load profiles and generally makes building equipment performance more visible in the load profiles. This is also an effective way to determine how effectively the facility is shutting down during low use periods.

Figure 13 shows a one-day load profile at a P\&DC on Christmas day. Christmas was selected as a day that would be expected to see reduced operation levels. Note that approximately every 1 to 2 hours there is a fairly consistent load of 100 to $150 \mathrm{~kW}$ cycling on and off. This doesn't necessarily indicate a problem, but should be investigated, initially by seeing if it is occurs on other load profiles for this facility. 


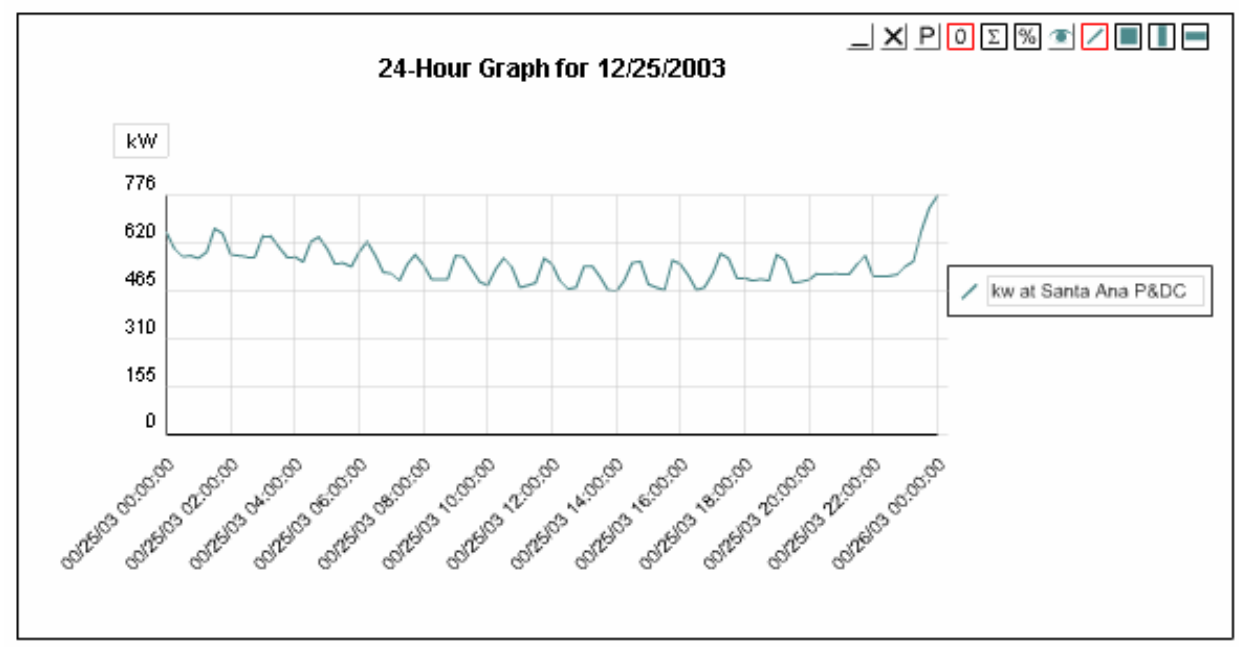

Figure 13. P\&DC daily load profile showing unusual load cycling

The next step would be to look at the same facility profile for other days for evidence of the same operation. The EIS programs allow several load profiles to be superimposed on the same chart. Figure 14 shows the profile for December 25 (shown in Figure 9) with the same day of the week for the adjacent 3 weeks added. It is not surprising to see overall lower load levels on the two Holiday days (December 25 and January 1). The profiles for January 8 and December 18 should be representative of normal work operations days.

The cycling pattern evident on December 25 does not appear on the other dates. It is therefore difficult to say with certainty the cause and implication of this observation. One possible explanation for the cycling load is an air compressor left on but was not in operation.

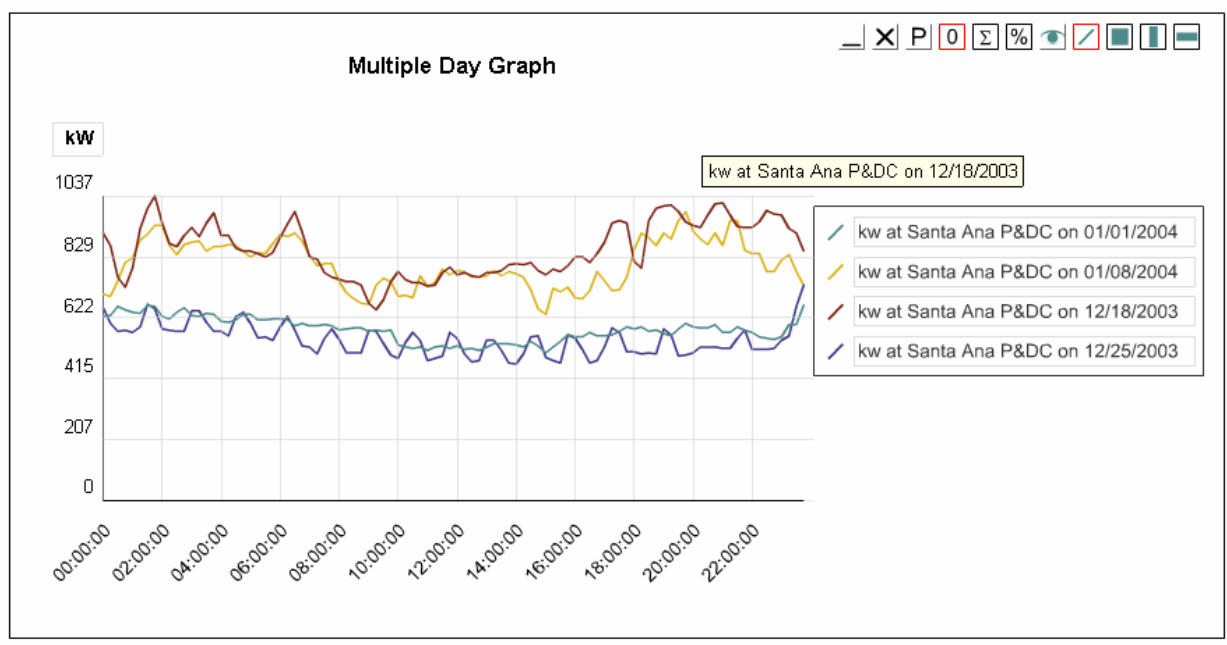

Figure 14. Four days load profiles at a P\&DC 
Viewing load profiles on days when workloads are light shows the facility's base load conditions. The facility profiled in Figure 14 maintains at least a $500 \mathrm{~kW}$ base load. High base loads generally offer significant opportunities for energy conservation measures, such as reducing energy use in unoccupied portions of the facility.

A challenge for larger facilities, where energy use is measured at the facility's main utility meter, is to get information on discrete areas of the facility and specific equipment. The EIS can be an effective tool but energy savings will only result from further investigation at the facility and implementation of energy saving measures.

User Tip: When comparing load profiles, it is best to minimize other variables. For example, compare the same day of the week, same period last year, or facilities with similar size and operation. 


\section{Benchmarking energy use levels}

If you don't know where you started, you won't know how far you've advanced.

Benchmarking your facility's energy use is the first step in effective energy management. A benchmark establishes a reference point for characterizing a facility's energy use and current operating practices.

\section{Benefits of Benchmarking}

Benchmarking allows you to:

- Identify and understand historical trends in energy consumption at your facility;

- Verify the effectiveness of energy efficiency and conservation measures;

- Detect inconsistent equipment operation across shifts or between facilities;

- Detect unusual equipment operation; and

- Track progress towards meeting energy reduction goals.

\section{Approach}

An energy manager can use the following approach with the EIS to develop and track energy benchmarks.

1. Compare progress from Same Period Last Year (SPLY)

2. Use the EIS to determine key baseline energy metrics for your facility (see Section 3).

3. Compare metrics for your facility to those of similar facilities.

4. Compare metrics between shifts at your facility

5. If energy conservation efforts are implemented, compare energy use before and after to assess the effectiveness of those efforts.

\section{Discussion}

The first step in benchmarking is to decide what energy metrics constitute the most useful benchmarks for your purposes. In most cases, facility managers will want to establish benchmarks for their facility's energy consumption and peak demand each month, since this information can be used to verify utility bills and also to establish seasonal energy metrics. If you have not already been tracking energy usage and peak demand levels for your facility, the EIS can be used to retrieve historical data.

To illustrate the process of retrieving historical data, Figure 3 shows a sample facility's one-year Summary Statistics. The summary provides a breakdown of energy use and maximum demand for weekdays and for weekend days for the selected period, along with the facility's load factor and date and time that the maximum demand occurred. These summary statistics can also be summarized on a monthly basis. Transferring the monthly data to a separate spreadsheet facilitates ongoing tracking. 
Normalize:

None
Account: 1393658655
Description: U S POSTAL SERVIC-11251 RANCHO CARMEL DR,SD

\begin{tabular}{|l|r|}
\hline Total Energy Usage ( kWh) & $14,710,148$ \\
\hline Total Weekday Energy Usage ( $\mathrm{W} / \mathrm{h})$ & $10,804,443$ \\
\hline Total Weekend Energy Usage ( $\mathrm{W} h)$ & $3,905,705$ \\
\hline Weekday Maximum Demand ( $\mathrm{kW})$ & 2,640 \\
\hline Weekend Maximum Demand ( kW) & 2,227 \\
\hline Load Factor & 0.6361 \\
\hline Total Energy ( kWh) & $14,710,148$ \\
\hline Maximum Demand ( kW) & 2,640 \\
\hline Maximum Demand Time & $08 / 14 / 200319: 15$ \\
\hline
\end{tabular}

\section{Figure 3. Annual Summary Statistics for a Sample Facility}

The UtilityVision summary is found under " 13 Month Report.” Figure 4 shows a sample 13-month report. To determine the annual energy use, you will have to manually total the 12 months. This is best done by transferring the data to a separate spreadsheet, and then performing the calculation.

\begin{tabular}{|c|c|c|c|c|}
\hline \multicolumn{5}{|c|}{ Data From: $12 / 22 / 02$ to $01 / 22 / 04$} \\
\hline Month & Year & Number of Readings & Total kWh & Maximum kW \\
\hline December & 2002 & 891 & 146,218 & 827 \\
\hline January & 2003 & 2,976 & 474,100 & 795 \\
\hline February & 2003 & 2,688 & 424,396 & 777 \\
\hline March & 2003 & 2,976 & 466,698 & 820 \\
\hline April & 2003 & 2,417 & 445,119 & 855 \\
\hline May & 2003 & 2,969 & 503,575 & 921 \\
\hline June & 2003 & 2,867 & 522,555 & 916 \\
\hline July & 2003 & 2,976 & 601,260 & 1,028 \\
\hline August & 2003 & 2,976 & 571,048 & 1,010 \\
\hline September & 2003 & 2,880 & 538,693 & 1,007 \\
\hline October & 2003 & 2,976 & 488,745 & 828 \\
\hline November & 2003 & 2,880 & 447,825 & 774 \\
\hline December & 2003 & 2,976 & 482,471 & 808 \\
\hline January & 2004 & 2,062 & 341,949 & 795 \\
\hline
\end{tabular}

Figure 4. UtilityVision "13 month report” 
UtilityVision User Tip: Copy and paste the 13-month data table into Excel to begin a monthly tracking spreadsheet. Use the paste special as HTML command to have data in most workable form.

The next step will be to develop benchmarks from the historical energy use that can then be used to compare with other facilities. The most common benchmark is done in units called "energy intensity," which is equal to the total annual energy use divided by the facility's gross square footage. Looking at facility energy use per square foot allows for a more meaningful comparison between Postal Service facilities of different sizes. Some EIS programs can be used to directly compute energy use intensity, while other require that the user perform the simple calculation manually. For example, the facility shown in Figure 4 has a floor space of 650,000 square feet. Thus the energy intensity is 22.63 kWh/sqft./yr. (= 14,710,148 kWh/yr / 650,000 sqft).

The energy intensity benchmark is also needed for annual federal agency energy reporting requirements. Most federal agencies are required to track and report annual energy use per square foot. This report combines electricity use with other fuels used in facilities, and thus is ultimately converted and reported in common units of millions of BTUs per square foot per year.

There are other benchmarks, such as comparison to SPLY, which can be developed for facilities, for example, by normalizing the annual energy use by occupancy level, hours of operation, or number of computers. Energy use is also dependant on the location's weather and climate. Benchmarking that accounts for weather and climate is best performed with software tools such as U.S. Environmental Protection Agency's Energy Star Portfolio Manager. This incorporates a typical year's weather data for various locations to normalize these effects on facility energy use. It also contains a large database of benchmarked buildings of various general types, some of which may be suitable for comparing with Postal Service facility’s energy use. 


\section{Using EIS to Facilitate Demand Response}

Electric utilities in California and many other states offer demand response (DR) programs that pay incentives to customers that are willing to reduce their demand during times when the reliability of the grid is threatened. Federal facilities are also occasionally called upon by their agencies to reduce electricity demand during periods when electricity supplies are tight. EIS can be used in a variety of ways to facilitate these efforts.

\section{Benefits}

Using EIS to facilitate demand response

- generates incentive payments for the customer,

- improves the reliability of the electric grid, and

- can reduce energy prices and costs for all electricity consumers

\section{Approach}

An energy manager can use their EIS to participate in DR programs in the following ways:

1. In conjunction with a facility audit, examine load profiles and key energy metrics to assess the quantity of load that might be available for curtailment during DR program curtailment periods

2. Use load control capabilities to automate load reductions during DR curtailment events

3. Monitor performance during DR program curtailment events

4. Review load profiles following DR program curtailment events to assess performance and verify utility incentive payments.

\section{Discussion}

Together, operations and facility personnel should determine what loads could be curtailed. Initial reviews should cover all time periods, even though utility demand response programs apply mostly to summer afternoon periods. By considering all time periods, other energy conservation opportunities will be discovered. Clearly, equipment needed for processing mail cannot be curtailed; however, other facility loads can often be curtailed including:

- Lighting - turning off lights in unoccupied areas and turning off some of the lights in areas of the building that have natural day lighting through windows or skylights.

- Office equipment -- Turning off office equipment not in use such as copiers, printers, computer monitors and other unnecessary plug loads. 
- $\quad$ Battery Chargers - Defer charging batteries in industrial vehicles until off-peak hours. Automated equipment can be installed to do this with manual overrides if necessary.

- HVAC equipment - Some HVAC equipment in Postal Service facilities with the UtilityVision EIS is now capable of running at one-half the power demand and can be controlled by the facility managers through the EIS systems. Comfort of the occupants is not adversely affected by this measure.

- Air Compressors - Turning off air compressors that are not in use can reduce demand and save energy. Otherwise, standby air pressure losses will cause compressors to turn on.

Any energy use data from submeters within the facility can be used to help assess the potential for specific equipment curtailments. At some facilities submetered HVAC systems or other equipment is accessible via the EIS. Data at the submeter level can also be useful to help assess the impact of load reduction efforts.

Next, consider time periods and durations that loads could be curtailed and the extent of curtailment. Utility demand response programs have different requirements that typically require at least $100 \mathrm{~kW}$ of demand to be reduced for 2 to 6 hours in duration.

Group loads by their method of control. Many loads are simply manually controlled with switches and on/off buttons, some may be on timers, and others may be controlled from an energy management system. Method of control is a factor in how quickly and efficiently the facility could respond in reducing demand.

A cost benefit assessment can be performed to determine what utility incentive levels are sufficiently beneficial to the Postal Service to reduce various levels of curtailable demand. The costs for curtailing demand include direct labor cost for shutting equipment off and a value for lost opportunity costs associated with the diverted labor for any curtailed processes. These costs set a minimum price incentive that is needed to economically justify participation in demand response programs. A systematic approach to conducting this type of assessment is described in Kintner-Meyer et al. (2003).

Understandably, facility managers initially prefer to manually turn off unnecessary lighting and equipment using existing controls when there are calls for demand reduction. During the electricity crisis, this was the most common approach.

\section{Utility Demand Response Programs}

The Postal Service routinely assesses the viability of participating in utility demand response programs. Electric utilities in California offer a variety of demand response programs. Each program has specific customer eligibility criteria (based on load size or rate schedule), incentive levels, advance notice time, conditions that trigger load reduction requests, and potential penalties. Detailed information on all these utility programs is available on SCE, PG\&E and SDG\&E utility websites. 
Participation in utility demand response programs is simplified and enhanced with webbased EIS. Postal Service facilities using the UtilityVision EIS have some curtailment options activated. Figure 15 shows a UtilityVision screen display for load curtailment setup. This allows a Postal Service manager to submit the time, duration, and load level they can curtail in response to utility notification. Figure 16 shows the load curtailment event-tracking screen where curtailment submittals and status can be viewed within UtilityVision. Some DR programs require customers to provide a firm committed load reduction, in exchange for an up-front "reservation" payment. The load curtailment tracking capabilities of EIS allow you to track actual performance relative to a baseline, to ensure that the load reduction commitment is met.

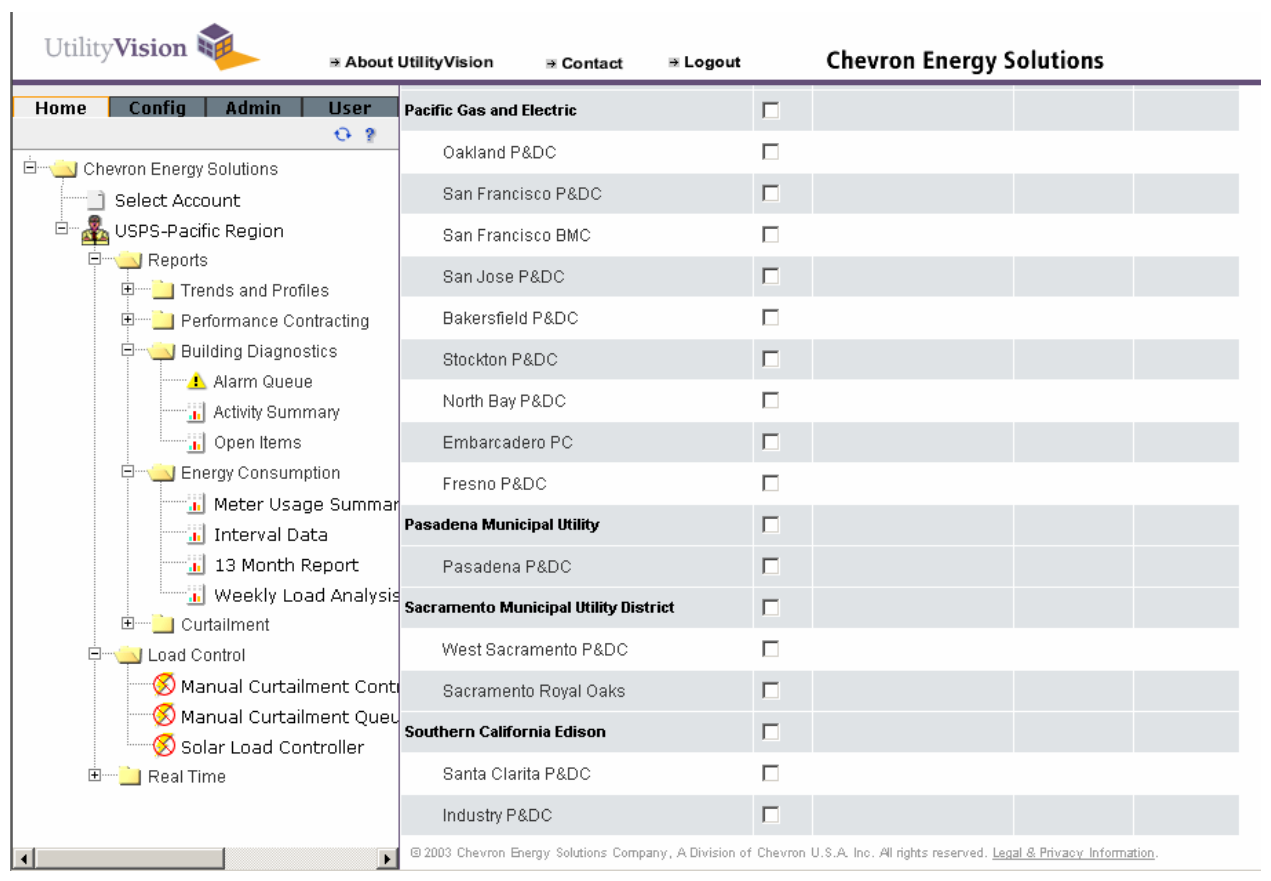

Figure 15. UtilityVision load curtailment setup screen 


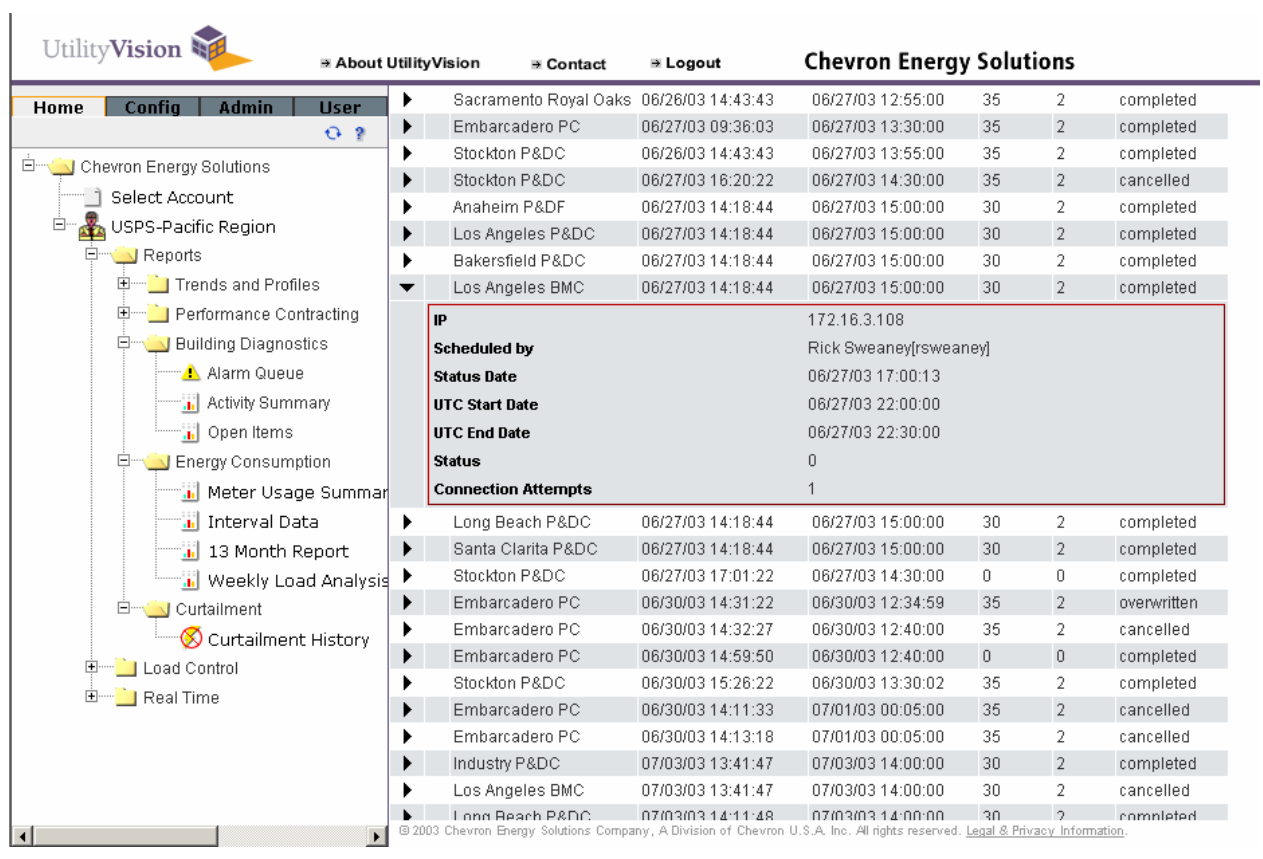

Figure 16. UtilityVision load curtailment history report 


\section{Creating a Routine for Tracking Energy Use}

This section provides suggestions and priorities for working with EIS and other facility energy management tasks. Table 2 shows key EIS reports and activities, with recommendations on the frequency that particular reports should be reviewed and activities performed.

\begin{tabular}{|c|c|c|c|c|}
\hline \multirow[b]{2}{*}{ EIS Activities } & \multicolumn{4}{|c|}{ Frequency of EIS Review } \\
\hline & Weekly & Monthly & Quarterly & Annually \\
\hline \multicolumn{5}{|l|}{ Facility Load Profile } \\
\hline Check for unusual patterns & $\mathrm{x}$ & & & \\
\hline Compare to historical load profiles & & & $\mathrm{x}$ & \\
\hline Compare to similar facilities & & & & $\mathrm{x}$ \\
\hline $\begin{array}{l}\text { Assess potential for DR program } \\
\text { participation }\end{array}$ & & & & $\mathrm{x}$ \\
\hline \multicolumn{5}{|l|}{ Load Duration Curve } \\
\hline $\begin{array}{l}\text { Assess potential for peak demand } \\
\text { reductions }\end{array}$ & & & $\mathrm{x}$ & \\
\hline Compare to historical patterns & & $\mathrm{x}$ & & \\
\hline Compare to similar facilities & & & & $\mathrm{x}$ \\
\hline \multicolumn{5}{|l|}{ Energy Metrics } \\
\hline $\begin{array}{l}\text { Compare daily peak demand and } \\
\text { energy use to applicable benchmarks }\end{array}$ & $\mathrm{x}$ & & & \\
\hline Verify utility bills & & $\mathrm{x}$ & & \\
\hline $\begin{array}{l}\text { Compare monthly energy use and peak } \\
\text { demand to historical trends }\end{array}$ & & $\mathrm{x}$ & & \\
\hline Re-assess historical trends & & & & $\mathrm{x}$ \\
\hline Compare to similar facilities & & & & $\mathrm{x}$ \\
\hline \multicolumn{5}{|l|}{ Annual Energy Report } \\
\hline Update data sections & & $\mathrm{x}$ & $\mathrm{x}$ & \\
\hline Submit report & & & & $\mathrm{x}$ \\
\hline
\end{tabular}

Table 2. Recommended schedule for reviewing EIS reports.

\section{Weekly reviews}

Though much EIS data tracking and analysis can be done on a less frequent basis, it is important to review some data on a weekly (or even daily) basis to identify unexpected load increases, changes in equipment operation, or demand spikes. It is much easier to identify the causes of such occurrences if investigated within a few days rather than several weeks later. 
Facility energy use, load profiles and peak demand levels should be reviewed on a weekly basis with the EIS. Energy use can be reviewed by looking at the facility's summary statistics. This will also provide the precise date and time of the facility's peak demand for the selected time period. Preferably in the same session, the energy manager can review the past week's load profile. Look for any anomalies in the load profile and significant variations in overall energy use and peak demand levels. Also verify that baseload levels are as expected. Energy is often wasted by not shutting down equipment and turning off lighting after operation hours. If anomalies or significant increases in usage are observed in the data, then tracking down the reason is important and can avert future unnecessary energy costs. Altogether, these weekly reviews should take less than 30 minutes.

\section{Monthly reviews}

Tracking energy use data on a monthly basis has several advantages. Monthly is generally the same period as the utility billing cycle, thus allowing for direct comparison with the utility bills. Monthly tracking is conducive to being part of a regularly scheduled routine action, without being so frequent to seem burdensome.

To use EIS data to verify utility bills, the facility energy manager should be receiving and reviewing a copy of the utility bills. To precisely compare the same time periods, it is important to review the EIS data for the same billing periods as the utility bill covers. It is recommended that a spreadsheet be used to track monthly energy use, billing demand, and utility costs. Other important EIS data to record for future tracking purposes includes: the number of days in the reporting month, total energy consumption, peak demand, and load factor. Include facility information at the top of the spreadsheet such as utility account and meter numbers, and facility square footage. A comment section for each month noting for any unusual occurrences such as a power outage or change in operational hours can be useful. Once the utility tracking spreadsheet is started with the basic energy use data, you will want to add more metrics such as the floor area to show energy intensity ( $\mathrm{kWh} / \mathrm{sq}$. $\mathrm{ft}$ ), variation from same period last year, or variation from other benchmarks you may choose.

The major electric utilities in California also have on-line billing data tracking systems, for which customer's can arrange access. As an example, SCE has a system called "Energy Manager" for on-line tracking of their large (>200 kW) customer's accounts. SDG\&E has a on-line system called "Energy Waves" for all customers. These programs save the past 12 to 18 months of energy use data. For large customers the information available typically includes a breakdown of energy use by utility time-of-use periods for each month, and total charges along with a breakdown of charges for energy, demand, taxes and other charges. The information in these tracking systems is based on the utility billing meter data, which is generally the same meter used to generate EIS data. The utility's database may supplement the EIS data and, providing that identical time periods are assessed, energy use data from the utility's on-line system should match the EIS data. 


\section{Quarterly reviews}

It is recommended that load duration curves and energy benchmarks be reviewed and updated on a quarterly basis (i.e. every 3 months). Since these values should not be changing significantly month to month, a quarterly review is generally acceptable. There is generally little to be learned by comparing energy use benchmarks with other facilities more frequently than on a quarterly basis.

\section{Annual reviews}

This is the time when all the work throughout the year simplifies annual reporting requirements. Federal agencies are required under a Presidential Executive Order to report their progress in reducing energy use on an annual basis. The Postal Service's annual energy report coincides with the Fiscal year (October 1 through September 30). The annual energy use levels are reported in units of MBTU/sq. ft. (million British Thermal Units per facility square foot) basis.

The Postal Service is on-track to meet the mandates of energy conservation and use of renewable energy sources. However, continued efforts are required to sustain the advances and find additional opportunities to use energy more wisely and more efficiently. EIS systems can be an important tool for Postal Service to achieve success. 


\section{Additional Information}

The following reports and websites provide additional information about the KWickview and UtilityVision EIS programs, EIS systems in general, and utility demand response programs.

\section{Postal Service EIS Support Documents}

KWickview User Guide. Increase your Energy Savings with KWickview: Your online Energy Monitor. SDG\&E. 2003. Contact SDG\&E at (866) 377-4735 for copies.

UtilityVision Training, USPS - Pacific Region. A Power Point presentation dated May 22, 2002.

\section{Published Reports}

California Energy Commission Technical Report. 2003. "Web-based Energy Information Systems for Energy management and Demand Response in Commercial Buildings.” October.

Kintner-Meyer, K., Goldman, C., Sezgen, O. and Pratt, D. 2003. "Dividends with Demand Response.” ASHRAE Journal. LBNL Report 52980, October.

Motegi, N., M.A. Piette, S. Kinney, and K. Herter. 2003. “Web-based Energy Information Systems for Energy Management and Demand Response in Commercial Buildings.” Lawrence Berkeley National Laboratory, LBNL-52510, April 18, 2003. Available on the web at: http://buildings.lbl.gov/hpcbs/Pubs.html

\section{Internet Resources}

A California Energy Commission website on enhanced automation systems for energy management, including useful links to electric utilities and demand response programs, can be found on the Internet at: http://www.consumerenergycenter.org/enhancedautomation/index.html

A report entitled “Operation \& Maintenance Best Practices: a guide to achieving operational efficiency” is available on the Internet at: http://www.eere.energy.gov/femp/techassist/pdf/omguide_frontmatter.pdf 